\title{
Multiple soaking with different solution concentration in doped silica preform fabrication using modified chemical vapor deposition and solution doping
}

\begin{abstract}
Incorporation of alumina (A12O3) into a silica matrix by modified chemical vapor deposition and a solution doping technique is investigated in this study. Multiple soaking cycles were used to increase the aluminum content in the core layer. The effect of alumina retention in silica matrix soot is focused by multiple cycles of soaking with different solution concentrations, while the effect of the adsorption mechanism is fixed by maintaining the soot deposition process (such as temperature $\left[1,800^{\circ} \mathrm{C}\right]$, precursor, total gas flow, and soaking time). The deposited soot is examined for porosity characteristics and effective surface area by a gas adsorption technique with Brunauer-Emett-Teller surface area analysis and the surface and cross-section morphology using scanning electron microscopy. Three different concentrations are used in this work $(0.3,0.7$, and $1.2 \mathrm{M})$ with multiple cycles of soaking. Sintering and the collapsing process is controlled for each preform. The result shows that the alumina content is increased substantially as the number of soaking processes is increased, which may be due to the retention effect as only a small amount of adsorption process takes place as indicated by the slight decrease in the surface area of soot. The collapsed preforms are analyzed using a preform analyzer. Energy dispersive x-ray spectrometry is used to check aluminum content and distribution into the core layer.
\end{abstract}

Keyword: Gas adsorption technique with Brunauer-Emett-Teller analysis; Modified chemical vapor deposition; Multiple solution doping process; Refractive index profile; Scanning electron microscopy-energy dispersive x-ray 